Article

\title{
Understanding Belonging and Community Connection for Seniors Living in the Suburbs
}

\author{
Sonya L. Jakubec ${ }^{1, *}$, Marg Olfert ${ }^{1}$, Liza L. S. Choi ${ }^{1}$, Nicole Dawe ${ }^{2}$ and Dwayne Sheehan ${ }^{1}$ \\ ${ }^{1}$ Faculty of Health, Community and Education, Mount Royal University, Calgary, T3E 6K6, Canada; E-Mails: \\ sjakubec@mtroyal.ca (S.L.J.), molfert@mtroyal.ca (M.O.), Ichoi@mtroyal.ca (L.L.S.C.), dpsheehan@mtroyal.ca (D.S.) \\ 2 Vivo for Healthier Generations, Calgary, AB T3K 6E3, Canada; E-Mail: ndawe@vivo.ca \\ * Corresponding author
}

Submitted: 14 December 2018 | Accepted: 5 March 2019 | Published: 18 June 2019

\begin{abstract}
While much has been explored about notions of both place and belonging in regard to community health of various populations, little is known of the phenomena specific to suburban dwelling seniors. More and more seniors are living in suburban neighborhoods, communities that do not tend well to the belonging needs of this population. This qualitative study sought the perspectives of suburban dwelling seniors about the role of belonging and community connection to their health and wellbeing. Informed by strengths-based approaches to community development and health, the study engaged people from three community groups of older adults in a Canadian suburb (a seniors' recreational/social group, and two cultural groups) in group interviews concerning the topic. Discoveries included an understanding of belonging as both personal and social, and identification of facilitators and barriers to belonging at personal and systemic levels. Belonging was experienced through connection, contribution and cooperation. These findings are important to shape community engagement with seniors and to inform decision-making and program developments in areas of recreation, leisure, health services, community policing, city planning and other services.
\end{abstract}

\section{Keywords}

community belonging; health; seniors; suburban; wellbeing

\section{Issue}

This article is part of the issue "The City, Aging and Urban Planning", edited by Matthias Drilling (University of Applied Sciences and Arts Northwestern Switzerland) and Fabian Neuhaus (University of Calgary, Canada).

(C) 2019 by the authors; licensee Cogitatio (Lisbon, Portugal). This article is licensed under a Creative Commons Attribution 4.0 International License (CC BY).

\section{Introduction}

Concepts of social connectedness and belonging have increasingly garnered the interest of researchers and interventionists over the past two decades (Almedom, 2005; Bruhn, 2009; Caxaj \& Berman, 2010; Ottmann, Dickson, \& Wright, 2006). While much has been explored about notions of both place and belonging regarding community health of various populations (Baldwin, 2014; Potvin \& Hayes, 2007), little is known of the phenomena of seniors living in suburbs (Richard, Gauvin, \& Gosselin, 2008). There are varied and inconsistent ways of describing suburbs, as well as recent discoveries of isola- tion experienced by urban and suburban dwelling seniors, with little understanding, however, of the older adults who live in these communities (Morris \& Pfeiffer, 2017). The phenomenon is one of rapidly increasing relevance in many Canadian cities where urban housing costs relegate many seniors to lower cost suburban regions, and where many new immigrant families also co-house in mixed generations (Miller, 2017; Patterson, Saddier, Rezaei, \& Manaugh, 2014). This study sought to explore the views and perspectives of seniors (older adults, 60+) living in the north central suburbs of Calgary, a large, multicultural and predominantly "young" (median age 36.4) city in Western Canada (Statistics Canada, 2012). 
Broad interests of this inquiry were about the experience of belonging and community connection to suburban dwelling seniors in relation to their health and wellbeing. Beginning the study with these interests and gathering the views of older adults who were already engaged in group activities was central to the project on a number of levels, namely providing seniors based in suburbs an opportunity to belong, to be heard and for their opinions to matter in community development. This knowledge is also important for decision-making and program developments in areas of recreation, leisure, health services, community policing, city planning and other services.

\section{Background}

Much has been explored internationally concerning older adults and the phenomenon of loneliness, including social and neighbouhood factors, over the past decade (Gerst-Emerson \& Jayawardhana, 2015; Smith, 2012; Vozikaki, Papadaki, Linardakis, \& Philalithis, 2018). Linkages between health and social networks are extremely complex and poorly understood, however-with numerous related variables of concern and relationships that defy empirical analyses. If we focus on understanding population-specific perspectives of community belonging there are a variety of frameworks and concepts to consider. Social cohesion (Bruhn, 2009; Toye, 2007), social connectedness (Almedom, 2005; Ottmann et al., 2006; Townsend \& McWhirter, 2005), social capital (Putnam, 1995), neighbourhood (Abada, Hou, \& Ram, 2007; Richard et al., 2008; Steptoe \& Feldman, 2001), communities (Völker, Flap, \& Lindenberg, 2007), and belonging (Block, 2008; Caxaj \& Berman, 2010) are all terms identified in the literature.

In empirical studies drawing upon these concepts or experiences, diverse approaches such as neighbourhood mapping (Aronson, Wallis, O'Campo, \& Schafer, 2007), indicator and demographic measurement studies (Nieminen et al., 2008; Rajulton, Ravanera, \& Beaujot, 2007), ecological (Pickett \& Wilkinson, 2008), comparative analyses (Green, Preston, \& Janmaat, 2006), and intervention studies (Pronyk et al., 2008) contribute to the growing literature. Despite a lack of clarity and inherent complexity, research studies have attempted to explicate the terms to be used and to appreciate relationships between these social factors and health concerns (see, for example, Grav, Hellzèn, Romild, \& Stordal, 2012, for a study on social support and depression). The linkages of belonging and loneliness of older adults are gathering current scholarly and programmatic interest, highlighting systemic and individual strategies for wellbeing (Goll, Charlesworth, Scior, \& Stott, 2015). Other meta-analyses have focused on understanding the quality and quantity of social relationships on mortality and taken together these factors are found to be comparable to other risk factors (Holt-Lunstad, Smith, \& Layton, 2010).

While the swell of conceptual and empirical work is building an understanding of community belonging and health (Mohnen, Völker, Flap, Subramanian, \& Groenewegen, 2013), little knowledge of the topic of belonging specifically for suburban dwelling seniors has been generated to date. A majority (66\%) of the Canadian population lives in some form of suburb and, given that one out of every four Canadians will be over the age of 65 in fewer than 25 years (Miller, 2017), the phenomenon of seniors living in the suburbs poses many important questions. Seniors in suburbs are unique because of perceived and real isolation from services, including health care and access to transportation (Patterson et al., 2014). Calgary's suburbs are inhabited by people of diverse social, cultural, and economic backgrounds. As such, our study engaged suburban-dwelling seniors engaged in diverse community groups for a broad, qualitative exploration of the phenomena to establish foundational understanding of the experience of belonging for suburban dwelling seniors.

Rather than relying on preconceived frameworks of understanding social connection and belonging, we wanted to hear the perspectives of people who identified as being connected to their community and, specifically, to hear the views of these older adults on belonging in relation to their wellbeing. In the study we asked the following questions: 1) what are the facilitators and barriers to belonging and connection, and 2) what, ideally, could belonging and connection look like in rapidly expanding, multi-cultural, multi-generational suburban communities?

\section{Research Methods and Approach}

This exploratory, qualitative study employed a group interview method with thematic analysis (Krueger \& Casey, 2009). The theoretical approach taken in this study design (one that guided the questions, as well as the methods and facilitation) was that of asset-based community development as described by McKnight and Block (2010) who problematize the practice of "professionalizing community", instead drawing on the notion of "abundant community", concerned with strengths rather than deficits related to experiences of belonging in communities. This strengths-based approach sought community learning and understanding of group experiences, rather than "medicalizing" or "professionalizing" community health and development in an outside framework of belonging (Block, 2008). Both the methods and this approach were appropriate to the broad exploratory and community development goals of the project. The study proceeded following ethical approval from a university level research ethics board.

\subsection{Participants}

Members of three distinct community groups for suburban-dwelling seniors comprised the sample for this study. The groups were already connected to the site of a large non-profit suburban recreation centre based in 
north central Calgary, and thus considered well qualified "expert informant" participants in terms of seniors' experiences of belonging. As introduced, Calgary is a youthoriented city that has experienced rapid growth with the resulting characteristics of decades of car-dependent suburban sprawl and consequent social isolation. The city experiences a long winter season for up to six months of the year with snow and ice and warm chinook winds, elements that were key to participant experiences of their community access and connection. Participants were sought who had found community affiliation and group participation within the suburban community in north central Calgary. Their experiences included navigating age-related changes in driving and mobility in the latter seasons of their lives within the context of the weather and suburban conditions, as well as changes of identity as a result of retirement from formal employment or family roles (Goll et al., 2015; Patterson et al., 2014).

Those recruited were retired seniors who were members of one of three distinct groups affiliated with the suburban recreation centre: a physical activity group from the local neighborhood association, a South Asian (Punjabi) cultural group that routinely met at the recreation centre, and a Chinese Canadian group of older adult neighborhood residents. A purposive snowball sampling technique was employed in the study and leaders from each of these community groups were approached to invite members to participate in a group interview process held at one of the community recreation centre group meeting rooms and the Chinese Elderly Citizens' Association where a volunteer interpreter/translator supported the data gathering. Confirmations were sought through the community leaders and 8 to 16 older adults (ranging in age from 60 to 80 years of age) participated in each of the three group interviews $(N=36)$. Approximately half of the total group identified as female, and half male.

\subsection{Data Collection and Analysis}

Data collection through audio recorded group interviews occurred over the course of 60 to 90 -minute group meetings and proceeded in three rounds, at a community meeting room selected by participants. The ChineseCanadian participant group interview was conducted in Mandarin, with English language translation provided for the recorded transcript. All other interviews took place in English language facilitated by two members of the research team. Interview questions asked were:

1. What does belonging in the community mean? How is community belonging and connection valuable for your neighborhood (for different groupsother individuals-you?)

2. What are the facilitators and barriers? What supports community belonging and connection in your neighbourhood? What gets in the way?
3. What would you like to happen? What would be happening-ideally-if there was community belonging and connection in your neighborhood? What would that look like?

Group interview analysis, as a form of thematic analysis, aims to capture themes elicited from group dialogue and relevant to group concerns (Braun \& Clarke, 2006). The analytic interest of our study was on experiences of community belonging identified by groups of suburban dwelling older adults. Research team members completed thematic analysis by hand-coding transcripts from all 3 group interviews. An initial reading of the texts allowed for researchers to "define" themes from the data, rather than searching for pre-defined themes or theoretically driven concepts of belonging (Braun \& Clarke, 2006, p. 92). During the first reading, notes were made of individual comments arising from the interviews in order to acquire a sense of the topics of benefits, barriers and desires for belonging embedded in the data. Later, text was manually highlighted, and notes were made in a data organizing form with the individual transcript reviews and broad themes were identified. It must be emphasized that this was not considered a-theoretical workcommunity development models guiding the project similarly framed the analysis of the interview data.

Participants reviewed the identified preliminary themes in a large group meeting, bringing together all three participant groups, as well as interested community agencies and municipal neighbourhood leaders, which allowed for confirmation of the findings. The collaborative research process also enabled an opportunity to seek resonance with those who hold expertise in the subject, work directly in the field, and those who were present at the interviews and part of the larger research team.

\section{Findings}

\subsection{Belonging Is Personal but Connected to Place and People}

Belonging was identified as a "feeling" (involving sensations and attitudes), a "knowing" (or having access to information and wisdom), a state of "being" (experienced in connection to others in defined community spaces), and as "doing" (activities and goings on). These characteristics were personal, but also connected or social, and are described in more detail with examples from the data. One participant described the social aspect of belonging in regard to the need for ongoing and sustained activities. He said:

We did a project last year and we had five communities come together from five different cultures and have five different events. That was great, but that was only limited to there and then; after that you forget again and don't get connected. Connecting means 
you should be connecting with everybody in the community, not just one group and the other group and the other group.

A "feeling" of belonging meant a sensation or an attitude, for example feeling attached, comforted, accepted, and appreciated/respected. For the participants, belonging also meant feeling they were seen or visible and feeling valued in a youth-focused city/culture:

It can be an isolated and abandoned feeling [described struggling to get to health resources or community activities for loved ones in need] - they just haven't built these necessary things in the suburbs.

Belonging, for the seniors, was a part of "having knowledge"-knowing information about what "what is happening" in the community, about the goings on in a neighbourhood beyond the family. Knowing the resources available, the gossip, and the best places to go and find things were all a key part of this belonging as a kind of knowing. A participant explained how knowledge was part of belonging:

Being connected is the comfort zone-knowing where to get help. It is scary when you don't know, as in when your partner is "going downhill" and you don't know where to turn. It is good to know who to approach; the facilities in your neighbourhood are helpful.

Not having knowledge in the community, it seemed, could have challenges or even bring "scary" consequences. At the other end of the continuum of knowledge, was a lack of belonging. According to a participant who sought out a community centre with translation and interpretation supports:

They [those struggling to belong] do not know where the community centre is or other centres of information....That's why they do not know where activities, events are and there isn't a sense of belonging at all.

"Being" part of something (more than home and family) was key to belonging in the community. This connection to something, beyond the bounds of one's home and family, included all sorts of differences (ages, ways of life, social status, culture and so on). In fact, the process of the group interviews and research study impacted this desire to connect, as seniors in one group asked about the other groups that would be participating in the study and requested a meeting with the other groups. Navigating these variances, however, was not easy. Being able to participate in the reciprocal relationship as a friend and a neighbour was generally identified as "harder as one gets older". Practicalities of life in suburban areas compounded these challenges, as well as the physical isolation and unfamiliar cultural connections challenging the participants. Despite this difficulty, participants emphasized that connecting to "something more" was important. Several participants noted that one's world could rapidly become small without expanding and diversifying one's social connections. One participant said it best as she commented:

Once you retire from work you lose that social circle and are cut off very quickly. Humans are social beings, sometimes seniors are happy at home, but some are looking for something outside their home-volunteer work, socializing, activities, etc.

Actively "doing" things (activities, meeting together, reading/gathering information, hearing from one another, or sharing ideas, customs and news) was another feature of belonging to community that was important for health and wellbeing. The gap in organized activities for those aged 50 to 75 was noted, with several participants emphasizing they "[we]re not old". One participant described it in this way:

There are just lots of stereotypes around what being "senior" means-we want to do things and feel alive and be part of things. There is also an individual responsibility. Sometimes you can know about things, but then the individual has to actually do something to act on it.

\subsection{Facilitators and Barriers to Belonging Are Both Personal and Systemic}

Factors that would facilitate or constrain a sense of belonging were also established in the group interviews and larger group analysis. The facilitators and barriers were, much like the meaning of belonging for participants, identified as both personal and systemic concerns. Participants confirmed that, in abundance, these factors would be facilitators, while if lacking would pose barriers to community belonging. Key factors influencing community belonging were thought to be hope, similarities, desire, effort, access and leaders.

Hope for connection with different people, organizations, research and community/city was a starting place to facilitate belonging. Without hope for belonging other factors could not be seen or supported. Participants expressed hope that "'something' will come from this [community engagement] work" that brought people together; others expressed hope that with their views and perspectives "on the record", that these opinions could be mobilized for other community development, grantwriting or other activities.

Similarities provided connection that was crucial to belonging, as did breaking through false separations that emerged from fears, habits and expectations. Separations emerged in particular when people were not alike, or when the interests seemed different on the surface (as in some of the generational or cultural differences). 
This need for similar interests was highlighted by a participant who said:

Similar interests are needed; people want to feel that they belong. Seniors attend [the] centre downtown because programs [are held] in Chinese, providing a common language, also dancing, exercise, Chinese newspaper [free on Fridays], singing, cooking.

At times the similar interests and activities that brought comfort and belonging to some people were viewed by others as exclusionary or barriers to belonging. Language was identified by some as a barrier in this way, where groups who met and engaged in the language of their origins, were points of contention. According to some participants, "people need to make an effort to learn English, to be Canadian". Some participants sought more dialogue and discussion-focused or segregated community activities (including activities with translators and interpreters) while others proposed activities that were more active than verbal (for example, games, dancing, singing, gardening and so on). Some participants explained that language was a barrier in many complex ways, for instance:

It's hard to be inclusive in this community. Lots of people are speaking their own languages, even if they can speak English. It [language] is a barrier to being inclusive.

Belonging in an extended community; learning from others; exercising and being active; seeking connections; trying (some) new things, required a strong desire and will. This desire took effort, and at times participants explained that others who might not feel a sense of belonging may be inhibited by their own will-perhaps as a result of fatigue, grief or loss or even illness, but regardless, a desire to belong was seen as essential. One participant explained how her recognition of the desire to belong emerged after retiring and becoming aware of how isolated she had become: "I didn't know people in the community, and didn't realize that I even wanted to until I stopped working".

The recognition and desire for belonging involved a certain curiosity that also existed in a tension with desires to keep things the same and distaste for change. Repeatedly, participants explained: "Sometimes change is hard for seniors". This conflicted curiosity and distaste for change revealed itself in terms of cultural learning and fears about cultures other than their own. Several participants placed an emphasis on learning more about diversity and particularly understanding cultural differences and strengths. This conflict was highlighted in the following interview comment regarding facilitators of belonging:

As with drinking and driving, education and awareness made a difference. The same with isolation and seniors mingling. We need to learn what makes other cultures good, how have they survived.
Another participant explained this learning in terms of family life and intergenerational belonging, as he explained the value of change and learning:

At first, I thought boys and girls should not spend time together, but I have changed my views on that.

Effort and openness, such as the effort to learn about cultural and generational changes, were facilitators to belonging. This effort required acceptance, give and take; getting past prejudices/judgments and an openness to change. Sometimes this openness was difficult, and required considerable effort, particularly when people may have experienced losses, fatigue or difficulties with mobility:

It is a two-way effort: You have to try to belong, but cultures sometimes make it difficult. A person might like to know where the community centre is, but they do not proactively find out.

Certainly addressing systemic issues (such as access to transportation) required effort, especially if meetings or events demanded transportation or language interpretation that was not assured. Personal factors to enhance openness and increase effort were identified as managing the sense of intimidation. Attending events in groups was helpful to manage intimidation. It was identified that more systematic ways of welcoming newcomers could be helpful for all groups:

Seniors are often intimidated by new things. Something could be in place to help newcomers integrate [to neighbourhoods or community groups], and also to help those in existing groups to be welcoming.

Access to physical and social connections was viewed as central to belonging. Facilitators (and barriers) included transportation; information; familiar language and translations; common places to meet (such as coffee shops and food courts as well as community and recreation centres), along with consistent routines that bring people together (i.e., every Friday newspapers, water fitness class on Tuesdays). It was clear that sustainability and consistency were important to participants who expressed interest in activities "at the same times and places...for consistency". These access issues were significant practical and physical barriers to belonging for suburban seniors. Participants highlighted the importance of access in the suburbs of a city like Calgary that does not routinely plow suburban side streets when snow falls, explaining:

How the hell do you get there [to a community gathering place]? Especially when the weather is inclement?

Access was also a point of controversy particularly in the suburban neighbourhoods that predominantly served young families. One participant emphasized the barriers 
as she described how:

The City is now building capacity for bicycles all over the place, to the tune of millions of dollars. This enhances life for younger people but not seniors.

Supporting the hope, will, and ways forward, seniors who are community leaders were identified as facilitators of belonging. These were the people who step up and nudge the connections and happenings in communities. They are also the ones who move forward community belonging and the needs of seniors in broader organizations and to municipal decision makers. At times, these leaders could see that they needed breaks and had to find others to hold up their leadership activities if they were on vacation or felt unwell.

Internal leadership and the activities of neighbourhood belonging contrasted with overly regulated or professional support. This professionalization of belonging was particularly noted by immigrant seniors, as in one participant who said:

In India, a neighbour would come over to help settle an argument; here [suburban Calgary] the police are called first.

Similar concerns were expressed by participants who described the barrier to belonging that emerged as a result of overly regulated volunteering and professionalization of community helping:

I can clean areas around the neighbourhood, but now there are regulations around who can do this, liabilities, so my small way of volunteering and belonging is shut down.

The effort to become involved and belong, or to step into leadership roles to try to understand the barriers were reflected on by participants. Some felt that, for those seniors not already active in suburban life, that a myriad of reasons impacted their belonging. Health, grief, language or other barriers were factors, but some participants also considered that professional helping and "programs" were barriers of sorts, creating dependencies and inhibiting people from seeking community support and belonging. It was bluntly put by one participant:

Why do some people make an effort and others don't? That is a whole other research study. There is a sense of entitlement. Some people are waiting to be catered to.

\section{Discussion, Implications and Limitations}

Belonging in the community is complex for seniors living in suburbs, particularly as these individuals and their neighbourhoods experience diversity and change. Olesen and Berry (2011, p. 194) found that social needs generally change across the life course, especially during the transition from paid work to retirement. Retirement and other losses are a feature of aging in any neighbourhood.

The diverse social and cultural groups of suburban dwelling seniors highlighted a variety of facilitators and barriers to belonging. Despite some unique differences, all expressed a desire for feeling connected and knowing others and the resources available; being active contributors in their communities and doing community work in cooperation with others across cultures and generations. Belonging, in this way, was both an aspect of individual identity and neighbourhood structures and experienced in connection to people and places; at times places were indeed held in much affection: "our walking track", "our Wednesday morning at the pool", "our coffee spot in the shopping mall", they said. The older adults' identities were understood only through places and a complex relationship of knowing, being and doing as affiliated and in connection to others.

Participants expressed a strong desire to be in connection with others particularly to share ideas and views in community, and to exchange information about daily activities, such as where to eat, how to access transport, and general support. Learning about others was identified as an essential component of connection. Connections within one's cultural group and with other groups were deemed as key to nurturing a sense of belonging. However, language remained a barrier for some in terms of being able to enact these connections. In Canadian and other suburban communities characterized by varied linguistic and cultural groups, needs for translation and other supports for older adults to engage more fully in community life are encouraged.

Desires to contribute were pronounced with an expression of the need for "give and take" or "a twoway effort". Seniors who admitted to not knowing the location of a local community centre recognized that they bore the responsibility to be proactive and find out its location and services offered. Giving back to the community-outside of the home and family-was an important aspect of belonging. Seniors expressed a desire to participate in maintaining their neighbourhoods and believed this could happen with support from community agencies. This emphasis on supportive programming needs was similarly found by Dare, Wilkinson, Marquis and Donovan (2018) in relation to fostering Australian seniors' community participation. The benefits of this belonging are noted by Olesen and Berry (2011, p. 194) who found that greater contact with neighbours and through volunteering was associated with improved mental health in newly retired people. Indeed, expanded information and supports for seniors' volunteering in suburban communities are recommendations that have emerged from this project.

Learning and exchanging knowledge together (across diverse generations and cultures) were aspects of belonging that were universally expressed. A common in- 
terest connected to community belonging in our study was learning with others and contributing to the knowledge of future generations. While seniors expressed concerns over the differences seen in the younger generation ("kids these days..."), the underlying sense of care and concern for the future was evident. Generational changes were sometimes viewed as difficult, but also necessary, and the tensions were accepted and appreciated by many as a part of community belonging. Mixed generation interventions are further highlighted in the growing field of intergenerational community health (VanderVen \& Schneider-Munoz, 2012). A sense of belonging as part of engagement with generational, cultural and other aspects of community diversity expressed by participants mirrors the perceived sense of expanded social support that can support mental wellbeing as discovered by Harasemiw, Newall, Mackenzie, Shooshtari and Menec (2018) and Reitz (2009).

The emergent understanding of belonging highlighted older adults' active engagement in their communities. This agency was part of the "two-way street" of community belonging emphasized by participants. Community access through information and physical means (transportation, road clearing and so on) are essential services to support belonging for older adults in suburbs. The belief that governmental organizations were responsible to meet their changing needs, was questioned by some participants with many challenging others about the need to accept new ways of doing things and giving way for progress and the next generation. Acceptance and use of public transportation and car sharing versus driving were particular examples of the variety of transportation options that could enhance belonging in suburban community life characterized by sprawl and car culture. This example of expanded access and use of public transportation may also provide the double benefit of sparking patterns of intergenerational connection many were seeking-after all, accessible transportation meets the needs of diverse ages and abilities within a population. Design elements that support driving in communities for older adults (Stav, Arbesman, \& Lieberman, 2008) and seniors' car sharing options (Shaheen, Cano, \& Camel, 2015) are further transportation possibilities to expand access and connection for seniors living in suburban communities. Further study and program evaluation in all these areas of information and physical design will be important future steps.

Despite being a fairly small scale, localized study with particular features of people and place, such as the diverse, new immigrant concentrated neighbourhoods and winter conditions in suburban Calgary-the topics of connection and isolation of seniors in suburbs (Pekmezaris et al., 2013; Zeitler \& Buys, 2015) and aspects of seniors' community decision making (Gallant \& Hutchinson, 2016) are of broad, current concern. In terms of societal and community health, these research discoveries are novel in the field. While drawing from diverse cultural groups, the study was limited in that it sought the views of well-seniors who were already connected to community supports and actively engaged in community life. This necessarily biased the findings, though it was indeed these views that were of interest at the time of the study. Future studies will approach participation differently to hear from seniors who are more isolated or not actively engaged in community connections. Seeking out these views will contribute to another set of questions and build a more complete picture of how belonging in community happens for suburban dwelling seniors, how this sense of belonging impacts individual and community health. Future studies, informed by knowledge of the meaning of belonging for seniors themselves, can then examine the impact of belonging (including yet unstudied concerns of racialization and discrimination specific to this population) and particular interventions on the health of suburban dwelling seniors.

This study is seen as a place to begin to understand the experience of community belonging for seniors living in suburban neighbourhoods. The results have provided valuable insights about seniors' desires and interests for community belonging for the community site where the study was based. Most specifically, for the participants themselves, this research process has given older adults an opportunity to engage in knowledge making and to connect with one another in ways that exemplified their desires for belonging through feeling, knowing, being and doing within community life. The group data analysis experience brought participant groups, who would otherwise not connect, together and enabled their collaboration in community activity planning. Understanding community belonging from those who experience it was a goal of the study, and sparking connections and activity was an unexpected and positive project by-product, providing an example of McKnight and Block's (2010) "abundant community".

\section{Conclusions}

This qualitative research project employed group interview methods to explore community health and belonging with seniors living in the north east/north central suburbs of Calgary, a culturally diverse western Canadian city of over a million people. The purpose was to gather the views and opinions of groups of seniors who were currently engaging in community recreation and social activities in order to inform future program planning and contribute to a beginning understanding of the issues of belonging and connection for suburban dwelling seniors.

When a sense of belonging and connection is recognized and nurtured, seniors wish to contribute to each other and the community as a whole. Belonging is a holistic experience of knowing each other, being active citizens, doing things to employ one's talents for the community and the next generations and a feeling of affiliation and connection. This desire for diverse connection and belonging itself was found to be a powerful resource through which all communities can benefit. The findings 
of the study have informed decision making and program development for seniors attending the recreation centre at the site of this project. The results and process of this work have also been shared with stakeholders such as city planners and health services. In addition, translation services, transportation and support for diverse groups and individuals to contribute to the community in various ways may benefit from these discoveries. Future lines of inquiry into the personal and structural supports of belonging will benefit multiple sectors concerned with urban planning and the growing older adult population living in suburban communities.

\section{Acknowledgments}

The authors acknowledge the administrative support of their home organizations, Mount Royal University and Vivo for Healthier Generations, as well as the contributions of participants and organizers with the participant groups in north-central Calgary. These older adults showed the potential of neighbourhoods, and generously shared their time, their personal reflections and their hope for belonging for all people in their suburban communities.

\section{Conflict of Interests}

The authors declare no conflict of interests.

\section{References}

Abada, T., Hou, F., \& Ram, B. (2007). Racially mixed neighborhoods, perceived neighborhood social cohesion, and adolescent health in Canada. Social Science \& Medicine, 65, 2004-2017. https://doi.org/10.1016/ j.socscimed.2007.06.030

Almedom, A. M. (2005). Social capital and mental health: An interdisciplinary review of primary evidence. Social Science \& Medicine, 61(5), 943-964.

Aronson, R. E., Wallis, A. B., O'Campo, P. J., \& Schafer, P. (2007). Neighborhood mapping and evaluation: A methodology for participatory community health initiatives. Maternal and Child Health Journal, 11(4), 373-383.

Baldwin, C. (2014). Assessing impacts on people's relationships to place and community in health impact assessment: An anthropological approach. Impact Assessment and Project Appraisal, 33(2), 1-6. https:// doi.org/10.1080/14615517.2014.983725

Block, P. (2008). Community: The structure of belonging. San Francisco, CA: Berrett-Koehler Publishers.

Braun, V., \& Clarke, V. (2006). Using thematic analysis in psychology. Qualitative Research in Psychology, 3, 77-101.

Bruhn, J. G. (2009). The group effect: Social cohesion and health outcomes. New York, NY: Springer.

Caxaj, C. S., \& Berman, H. (2010). Belonging among newcomer youths: Intersecting experiences of inclusion and exclusion. Advances in Nursing Science, 33(4), E17-E30.

Dare, J., Wilkinson, C., Marquis, R., \& Donovan, R. (2018). "The people make it fun, the activities we do just make sure we turn up on time". Factors influencing older adults' participation in community-based group programmes in Perth, Western Australia. Health \& Social Care in the Community, 26(6), 871-881. https://doi.org/10.1111/hsc.12600

Gallant, K., \& Hutchinson, S. (2016). Perceptions of power within a membership-based seniors' community center. Leisure Sciences, 38(4), 357-372. https:// doi.org/10.1080/01490400.2015.1095660

Gerst-Emerson, K., \& Jayawardhana, J. (2015). Loneliness as a public health issue: The impact of loneliness on health care utilization among older adults. American Journal of Public Health, 105(5), 1013-1019. https:// doi.org/10.2105/AJPH.2014.302427

Goll, J., Charlesworth, G., Scior, K., \& Stott, J. (2015). Barriers to social participation among lonely older adults: The influence of social fears and identity. PLoS One, 10(2). https://doi.org/10.1371/journal. pone.0116664

Grav, S., Hellzèn, O., Romild, U., \& Stordal, E. (2012). Association between social support and depression in the general population: The HUNT study, a crosssectional survey. Journal of Clinical Nursing, 21(1/2), 111-120.

Green, A., Preston, J., \& Janmaat, J. G. (2006). Education, equality and social cohesion: A comparative analysis. New York, NY: Palgrave Macmillan.

Harasemiw, O., Newall, N., Mackenzie, C. S., Shooshtari, S., \& Menec, V. (2018). Is the association between social network types, depressive symptoms and life satisfaction mediated by the perceived availability of social support? A cross sectional analysis using the Canadian Longitudinal Study on Aging. Aging and Mental Health, 8, 1-10.

Holt-Lunstad, J., Smith, T. B., \& Layton, J. B. (2010). Social relationships and mortality risk: A meta-analytic review. PLoS Med, 7(7), e1000316. https://doi.org/ 10.1371/journal.pmed.1000316

Krueger, R. A., \& Casey, M. A. (2009). Focus groups: A practical guide for applied research (4th ed.). Thousand Oaks, CA: Sage Publications.

McKnight, J., \& Block, P. (2010). The abundant community: Awakening the power of families and neighborhoods. San Francisco, CA: Berrett-Koehler Publishers.

Miller, G. (2017). No place to grow old: How Canadian suburbs can become age friendly (IRPP Insight Report March 2017/14). Montreal: Institute for Research on Public Policy. Retrieved from http://irpp.org/wpcontent/uploads/2017/02/insight-no14.pdf

Mohnen, S., Völker, B., Flap, H., Subramanian, S., \& Groenewegen, P. (2013). You have to be there to enjoy it? Neighbourhood social capital and health. European Journal of Public Health, 23(1), 33-39. https:// doi.org/10.1093/eurpub/cks039 
Morris, E., \& Pfeiffer, D. (2017). Who really bowls alone? Cities, suburbs, and social time in the United States. Journal of Planning Education and Research, 37(2), 207-222. https://doi.org/10.1177/ 0739456X16647160

Nieminen, T., Martelin, T., Koskinen, S., Simpura, J., Alanen, E., Härkänen, T., \& Aromaa, A. (2008). Measurement and socio-demographic variation of social capital in a large population-based survey. Social Indicators Research, 85(3), 405-423.

Olesen, S., \& Berry, H. (2011). Community participation and mental health during retirement in community sample of Australians. Aging \& Mental Health, 15(2), 186-197. https://doi.org/10.1080/13607863. 2010.501053

Ottmann, G., Dickson, J., \& Wright, P. (2006). Social connectedness and health: A literature review (GLADNET collection Paper 471). Ithaca, NY: Cornell University ILR School. Retrieved from https:// digitalcommons.ilr.cornell.edu/cgi/viewcontent.cgi? article $=1474 \&$ context $=$ gladnetcollect

Patterson, Z., Saddier, S., Rezaei, A., \& Manaugh, K. (2014). Use of the urban core index to analyze residential mobility: The case of seniors in Canadian metropolitan regions. Journal of Transport Geography, 41, 116-125. https://doi.org/10.1016/j. jtrangeo.2014.08.013

Pekmezaris, R., Kozikowski, A., Moise, G., Clement, P. A., Hirsch, J., Kraut, J., \& Levy, L. C. (2013). Aging in suburbia: An assessment of senior needs. Educational Gerontology, 39(5), 355.

Pickett, K., \& Wilkinson, R. (2008). People like us: Ethnic group density effects on health. Ethnicity \& Health, 13(4), 321-334. https://doi.org/10.1080/ 13557850701882928

Potvin, L., \& Hayes, M. V. (2007). Place and health research in Canada. Canadian Journal of Public Health/Revue Canadienne de Sante'e Publique, 98, S6-S7.

Pronyk, P. M., Harpham, T., Busza, J., Phetla, G., Morison, L. A., Hargreaves, J. R., . . Porter, J. D. (2008). Can social capital be intentionally generated? A randomized trial from rural South Africa. Social Science \& Medicine, 67(10), 1559-1570.

Putnam, R. D. (1995). Bowling alone: America's declining social capital. Journal of Democracy, 6(1), 65-78.

Rajulton, F., Ravanera, Z. R., \& Beaujot, R. (2007). Measuring social cohesion: An experiment using the Canadian national survey of giving, volunteering, and participating. Social Indicators Research, 80(3), 461.

Reitz, J. G. (2009). Multiculturalism and social cohesion: Potentials and challenges of diversity. New York, NY: Springer.

Richard, L., Gauvin, L., \& Gosselin, C. (2008). Staying connected: Neighbourhood correlates of social participation among older adults living in an urban envi- ronment in Montreal, Quebec. Health Promotion International, 24(1), 46-57. https://doi.org/10.1093/ heapro/dan039

Shaheen, S., Cano, L., \& Camel, M. (2015). Exploring electric vehicle carsharing as a mobility option for older adults: A case study of a senior adult community in the San Francisco Bay area. International Journal of Sustainable Transportation, 10(5), 406-417. https:// doi.org/10.1080/15568318.2014.962675

Smith, J. (2012). Toward a better understanding of loneliness in community-dwelling older adults. The Journal of Psychology, 146(3), 293-311. https://doi.org/ 10.1080/00223980.2011.602132

Statistics Canada. (2012). Census metropolitan area of Calgary: Calgary age distribution. Statistics Canada. Retrieved from https://www12.statcan.gc.ca/ census-recensement/2011/as-sa/fogs-spg/Factscma-eng.cfm?LANG=Eng\&GK=CMA\&GC $=825$

Stav, W., Arbesman, M., \& Lieberman, D. (2008). Background and methodology of the older driver evidence-based systematic literature review. American Journal of Occupational Therapy, 62(2), 130-135. https://doi.org/10.5014/ajot.62.2.130

Steptoe, A., \& Feldman, P. J. (2001). Neighborhood problems as sources of chronic stress: Development of a measure of neighborhood problems, and associations with socioeconomic status and health. Annals of Behavioral Medicine, 23(3), 177.

Townsend, K. C., \& McWhirter, B. T. (2005). Connectedness: A review of the literature with implications for counseling, assessment, and research. Journal of Counseling and Development, 83, 191-201.

Toye, M. (2007). Social cohesion: The Canadian urban context. Ottawa: Parliamentary Information and Research Service.

VanderVen, K., \& Schneider-Munoz, A. J. (2012). As the world ages: Attaining a harmonious future world through intergenerational connections. Journal of Intergenerational Relationships, 10(2), 115-130. https://doi.org/10.1080/15350770.2012.673972

Völker, B., Flap, H., \& Lindenberg, S. (2007). When are neighbourhoods, communities? Community in Dutch neighbourhoods. European Sociological Review, 23(1), 99-114. https://doi.org/10.1093/esr/ jcl022

Vozikaki, M., Papadaki, A., Linardakis, M., \& Philalithis, A. (2018). Loneliness among older European adults: Results from the survey of health, aging and retirement in Europe. Journal of Public Health, 26(6), 613-624. https://doi.org/10.1007/s10389-018-0916-6

Zeitler, E., \& Buys, L. (2015). Mobility and out-of-home activities of older people living in suburban environments: 'Because I'm a driver, I don't have a problem'. Ageing \& Society, 35(4), 785-808. https://doi.org/10. 1017/S0144686X13001086 


\section{About the Authors}


Sonya L. Jakubec is a Professor in the School of Nursing and Midwifery at Mount Royal University. She is a Registered Nurse and community health researcher with a focus on social inclusion, belonging and multiple levels of intervention. The author of several articles and books in community health nursing, mental health and research literacy, Sonya's research program is concerned with lifespan wellbeing, including palliative care for those who experience structural vulnerabilities, social support for older adults and caregivers, and the connection of parks and natural places and health/wellbeing.

Marg Olfert holds graduate degrees in both nursing (University of Saskatchewan) and education (University of Calgary). She has a professional background in adult surgical nursing, critical care, and cardiology as well as nursing education and leadership. Her research interests include nursing history, interprofessional education, community development, seniors' health and belonging, licensure examination preparation and collaborative nursing programs.

Liza L. S. Choi is an Associate Professor in the School of Nursing in Midwifery at Mount Royal University. Liza's academic interests focus on diverse population health, and she has investigated the critical success factors for learning in English-as-an-Additional-Language among nursing students, online learning in the area of diversity and health along with studies of societal factors that impact the health of elderly (Chinese) Canadians and the use of electronic health tools to improve the health of patients.

Nicole Dawe holds an MBA from Memorial University in her home province of Newfoundland and Labrador on the east coast of Canada. She has a passion for integrating community building and storytelling into everything. She is currently sharing those gifts in development and leadership with the north-central Calgary's "Vivo for Healthier Generations", a large recreation, research and innovation hub on a mission to raise healthier generations and achieve their optimal health wherever they choose to live, work and play.

Dwayne Sheehan is an Associate Professor at Mount Royal University in Calgary Canada. His recent work in the area of physical literacy extends beyond the classroom and into the community. He collaborates extensively with municipal recreation, parks, charities and other leisure partners in conducting applied research related to physical literacy and community health. Dwayne is also an Adjunct Professor at the University of Calgary in the Faculty of Kinesiology. 